\title{
The production and politics of urban expertise: contesting transport in Auckland, New Zealand
}

March 30, 2018

\begin{abstract}
Expert technical knowledge has a central role in decision-making for urban transport and is subject to public scrutiny for major investments. This paper examines how expertise is produced and contested by advocacy groups in Auckland, New Zealand. A network of advocates has emerged, garnering considerable influence as 'experts' on urban transport and planning. In response to the perceived over-reliance on outdated approaches to transport, advocates mobilised alternative expertise using blogs and social media. Internet platforms enabled groups to extend the public sphere online, creating spaces for deliberation and contestation. Their activities targeted the technocratic logics embedded in forecasting models, reasserted transport infrastructure's function as urban space, and highlighted how transport infrastructure shapes everyday experience. This case shows how advocates countered the postpolitical condition by re-ordering the polity of transport in Auckland. Advocates have been instrumental in appropriating globally-mobile policies and successfully promoted improvements to public transport and cycling. However, those interviewed showed limited consideration of equity issues related to income, race and gender. This raises questions over whether the expertise mobilised favoured privileged groups, as advocates may be unaware of marginalisation that they rarely experience themselves. Alliances with community groups and local researchers can support broader engagement with distributional issues.
\end{abstract}

\section{Introduction}

Urban governance is an increasingly technical matter (Hodson et al. 2012), and urban politics frequently turn on socio-technical controversies regarding the built environment, transport, social equity and environmental sustainability. Therefore the production and mobilisation of expert knowledge are central to the way that cities are governed to face future challenges of increased urbanisation, environmental risks and social disparities. The validity of different forms of expert knowledge is particularly contentious for urban transport. Decision-making processes utilise knowledge generated by a range of technical tools for economic analysis, transport modelling and forecasting. A brief survey of cities across the globe reveals how local transport history, legacy investments, government capacity and mobility cultures have a profound influence on the dominant transport modes, level and quality of services. 
This paper examines the production of urban knowledge and contestation by urban planning and transport advocates, drawing from a case study set in Auckland, New Zealand. The study scrutinises the alternative discourses promoted by advocates, and the tactics employed to contest expert knowledge, drawing from semi-structured interviews and analysis of knowledge mobilisation through social media. The case was selected after observing a relatively small group of advocates garner considerable influence and credibility in their local context, without any official authority. This observation raised questions over what and who constitutes an expert within knowledge production, and how the mobilisation of knowledge is used to counter the postpolitical condition that dominates urban transport planning.

\section{Background}

Expert knowledge carries intrinsic power, and dominant discourses amongst experts often embody normative thinking that can be stifling and "imposes a rigid framework of what is 'good' and what is 'evil' in cities"(Kirby, 2013). Urban expertise is a hybrid field of knowledge, comprising a range of oftenconflicting claims arising from planning, economics, engineering, sociology and political sciences (Van Damme, 2013). This study examines urban knowledge as a socially-constructed outcome: a hybrid of how we know and experience the city and the epistemologies emerging from technical disciplines. As shown by Healey and Hillier (1996), non-state actors perform a specific kind of communicative work through their contribution of a series of statements and truth-claims: 'knowledge and values are generated, positions are asserted and rendered legitimate through the making of statements, the development of arguments and the assertion of claims to policy attention'. In this way, elaborating on contested issues and the claims brought forth by advocacy groups reveals how forms of expert knowledge are constructed (and deconstructed), and the underlying politics.

\subsection{Knowledge production and the postpolitical condition}

Social processes are essential to produce knowledge: communicative actions, translation between disciplines, and the synthesis of knowledge across technical and non-technical domains. Examining these social processes can reveal the implicit assumptions and norms embedded within expert knowledge, and shed light on the validation and appropriation of knowledge that emerges from outside the local context. Transport planning draws from diverse forms of knowledge: embodied local knowledge on public expectations, environmental or cultural challenges, and prominent political issues related to transport; technical or codified knowledge on network characteristics, capacities; practice-centred knowledge on 'best practice' planning and traffic engineering that determines the use of specific paradigms of analytical approaches; and political knowledge of what is possible given local power dynamics and authority of different institutions (Vigar 2017).

Technical and practice-centred knowledge has a performative dimension, conveying to practitioners a degree of objectivity, validity and certainty, arising from the analytical model or professional experience that sits behind them. This performativity is shown by Kebłowski and Bassens (2017), who show that transport policy "involves a language imbued by mathematical models and technical knowledge... methodologies have given transport an aura of an almost uniformly 'expert'-led, highly 
technical, and essentially 'rational' scientific discipline coded in mathematical language". These forms of knowledge act to depoliticise transport and undermine possibilities to consider the social or political dimensions. In this way, urban knowledge is frequently depoliticised and the notion of the urban 'postpolitical' condition (Swyngedouw, 2010). This notion is a particular form of depoliticisation that 'mobilis[es] a vast array of experts' (Zizek, 1999) [p. 204] and delegates decision-making to quasi-autonomous government agencies or the private sector. This condition does not imply an absence of politics, but rather the re-ordering of politics and possibilities for emancipatory change (Swyngedouw, 2017). As shown by Legacy (2016) the restriction of debate within traditional channels of public consultation led interest groups to seek out new opportunities to politicise the issue by creating 'their own informal deliberative and democratic spaces - whether they are public forums where knowledge and information can be exchanged, preparing economic arguments in favour of alternative transport projects, or appearing on local television and radio programmes to present the case against the East West Link'. Controversies over transport investments reveal how technical expertise can be manipulated for political purposes, leaving a legacy for a city's physical form (Bocking 2006). Historical trajectories of urban development, geographical characteristics, planning paradigms and path-dependence in decision-making provide partial explanations for different regional approaches to transport provision (Harris, 2005).

Knowledge production takes place across multiple spatial scales, from local sources to international knowledge circuits (McCann, 2010). Expert knowledge of urban transport policy and planning is globally mobile (Peck, 2011), shown by the transfer of bus rapid transit (Wood, 2015) and congestion charging (Borjesson et al. 2014. Cohen 2017). The transfer of mobile policies is usually only partial (Marsden et al. 2012), and policy outcomes vary according to the local context. The activities of advocacy groups provide a valuable lens to examine the intersection of global circuits of policy knowledge and local production of urban knowledge, embedded within the postpolitical condition. To drive for policy change, advocacy or interest groups function as social networks that mobilise and disseminate knowledge.

The internet, as a platform for communication and mobilisation of knowledge, is becoming central to social action in cities: planning and transport agencies provide information and materials online, enabling activists to disseminate and comment on them more rapidly, and to a much wider audience (Trapenberg Frick, 2016). For example, community groups advocating against urban intensification in Sydney used social media to form tactical coalitions across diverse sets of stakeholders and facilitate learning between groups (Williamson and Ruming, 2017). The internet also facilitates transnational flows of information and expert knowledge, creating a multitude of new global circuits of policy knowledge. Before the proliferation of internet communications, these knowledge circuits comprised networked epistemic communities of local policymakers, globe-trotting consultants and informational infrastructures' such as professional organisations and international institutions such as UN-Habitat and the OECD (McCann, 2010). At the current time, the internet is increasingly popular as a tool for social mobilisation and is dramatically shifting the structural properties of the public sphere and dominant modes of public deliberation (Castells 2008). Internationally, blog sites have become prominent in some Western cities, contributing to public debate - including Streetsblog across a number of American cities, Second Avenue Sagas in New York, and MayorWatch in London. Blog sides draw from local events and urban issues, as well as wider circulations of knowledge from urban media sites such as Citylab Planetizen and Guardian Cities These overlapping spheres of knowledge production, translation and dissemination have received limited academic attention, despite having a 
significant influence on public attitudes and engagement with urban issues.

\subsection{Urban advocacy}

Advocacy by activist and community-based organisations in cities arise from concerns over equity or special interests, although the politics adopted by advocates vary widely.

Groups can coalesce around radical political movements such as Occupy, opposition or support for specific projects or policies, or motivations for social or racial justice (Mayer 2013). However, an alternative approach, broadly termed 'progressive urbanism' (Stehlin and Tarr 2017) or 'tactical urbanism' (Mould, 2014), adopts a distinctly different mode of urban politics. Epitomised by advocacy groups promoting cycling and urban agriculture in California, this approach to politics avoids the explicitly political advocacy that draws from 'narratives of disinvestment, segregation and discrimination', and instead promotes a 'framework of spatial improvement achievable through enlightened governance'. While the future vision of the city may be similar, the justification for this, and means for achieving it follow an approach that positions urbanists as the central agents of change in a struggle against powerful interests. However instead of directly challenging these interests, their proposals promote 'a depoliticised consensus goal of creating better urban places... the value of the local, they work to show, matters to everyone - it can increase property values, consumption, and investment, as well as overall quality of life.' (Stehlin and Tarr 2017). Critique of this mode of advocacy argues that it privileges design solutions as a technocratic fix to social problems, instead of directly challenging the economic systems of production, consumption, and capital accumulation that are central drivers of inequality. It also highlights the positionality of actors involved, described as 'advocates who have adeptly positioned their obstructed efforts at placemaking as part of a much grander fight for the future fortunes of the city. The effect is that people, such as white, male, bicycle advocates, who have rarely been marginalised by their racial, ethnic or class subject positions come to understand themselves as underdogs by championing cycling and gardening... A politics of urban quality of life that is dislocated from issues related to patriarchy, class power and racism has a blunt critique, limited potential for alliances, and vulnerable to capture by the same powerful interests who profit disproportionately from urban development' (Stehlin and Tarr 2017). In this case, progressive urbanism unwittingly undermined its efforts by overlooking the inherently distributional impacts to the politics of urban planning and transport. Therefore in the context of advocacy and expert knowledge, a closer examination of knowledge production can reflect on its influence to shape urban policies and community interventions to improve environmental sustainability and social equity. Expert knowledge is particularly relevant for transport because the required infrastructure investments are capital-intensive, physically expansive and require significant input from technical experts such as economists and engineers to plan and deliver projects.

\section{Case study}

This case comprises a relatively new group of advocates, networked across several groups that are based in, and primarily lobby for urban transport policy in Auckland, New Zealand. Auckland is New Zealand's largest city, the population of around 1.4 million people comprises one-third of New 
Zealand's population.

A brief review of Auckland's transport history is important to foreground this analysis: until the 1950s, Auckland had a tram network and high public transport patronage, peaking at 420 annual trips per capita during World War II (Bush 2014). Following the removal of the tram network and construction of a motorway system in the $1950 \mathrm{~s}^{1}$, Auckland's population made a dramatic shift to private vehicle travel, and by 1995 annual trips per capita had fallen to around 33 trips per capita. Since the amalgamation of the city's governing authorities in 2010. Auckland's transport is the responsibility of a unitary authority and integrated transport provider. The accelerated pace of transport improvements and reinvestment into rail, bus and cycling infrastructure has facilitated strong growth in public transport use to an average 54 annual trips per capita, although travel by car remains a dominant way of getting around the city. Transitioning to sustainable urban transport is challenging as automobile-dominant transport planning is embedded in national transport policies (Hickman 2014 Imran 2015), creating barriers to environmentally sustainable travel modes (Chapman et al. 2017). Additionally, disagreement between the local and central government agencies has led to protracted decision-making processes for public investments (McArthur 2017). While the new government elected to power in late 2017 favour for the significant expansion of public transport services, social attitudes to travel are still dominated by views that private vehicle ownership is a necessity (Bean et al. 2008).

Over the past decade, a small number of advocacy groups have emerged to become vocal and highly influential commentators and advocates for transport policy in Auckland and also at the national level. The transport manifesto proposed by New Zealand's recently-elected Labour coalition government included two major projects conceived and lobbied for by the groups included in this case study (Labour 2017). First, the Congestion Free Network 2.0, an upgraded scheme for the city's transit network, comprising new light rail and bus rapid transit lines, heavy rail upgrades, and limited-stop bus services. Second, the Regional Rapid Rail project proposes a passenger rail service linking Auckland with two other cities in the wider region.

The emergence of these groups has reshaped the political ecology of transport in Auckland. Historically, tensions between Auckland's governing bodies and the central government, based in the smaller city of Wellington, dominated the politics of transport. Since the shift away from railbased transit to cater for private vehicles in the 1950s (Mees and Dodson 2007), there has been ongoing campaigning for improved rail upgrades by some local politicians, although institutional restructuring, a lack of funds and ongoing reluctance to commit to the costs of rail infrastructure frustrated these efforts (Bush, 2014). In recent years the remarkable change observed is the new public discourse on transport, with clear impacts on elected officials' willingness to support public transport improvements and greater awareness of sustainable mobility amongst transport and urban planning professionals. Table 1 summarises the four groups included in this case study. All four groups espouse the principles of New Urbanism: promoting mixed-use, transit-oriented development, public transport or active travel modes, environmentally sustainable transport infrastructures and improvement of the urban realm. All four organisations are active on Twitter, and except for the War for Auckland, run by volunteers.

Table 1: Interviews conducted with advocacy groups 


\section{Methodology}

A mixed-methods approach combined ethnographic interviews with advocates and spatial analysis of knowledge mobilities exhibited through social media use. Interviews sought to gather individual perspectives on expert knowledge production and the performative role of urban 'expertise' for Auckland's transport. This method elicited in-depth knowledge and argumentation around the contestation of government agencies' knowledge claims by advocacy groups in Auckland. This approach intentionally focuses on the activities and experiences of advocates, without making judgements on whether government agencies were necessarily right or wrong in their application of expert knowledge.

Combining interviews with analysis of the geography of social media communications helped understand how internationally-mobile policies interplay with local advocacy. Twitter offers a platform to create weak ties with other users from anywhere in the world. However empirical studies show that despite the potential for long-range ties, Twitter users tend to engage more with other users in the same metropolitan area (Takhteyev et al. 2012). The ease of communication with both long and short-range ties on Twitter is particularly relevant to understand policy mobilities and the potential for knowledge transfer. Twitter data was sourced from Twitter's filtered streaming API, for March 2017. The initial sample of 3200 tweets was filtered to only include users with a geographic location, reducing the sample size to 1589. Twitter activity from the War for Auckland was not included since this initiative did not have a dedicated Twitter account.

Eight interviews with current and former members of four groups took place between 2015-2016, ranging from 45-90 minutes in length. Given the small size of these groups, the number of potential interviewees was relatively small, and snowball sampling was used to access as many interviewees as was feasible. Interview transcripts were coded and analysed thematically, first to articulate the main points of contestation over expert knowledge and subsequently to draw out the tactics adopted by groups and actors to counter these. The following sections elaborate on emergent themes, drawing from advocates' accounts of their experiences.

\section{Alternative discourses and contested norms}

Contestation over expert knowledge centred on two fundamental and interconnected issues: firstly, a perceived disconnect between the conceptualisation of transport within decision-making by local and national authorities, and the empirical reality of transport behaviour and preferences in Auckland. Secondly, advocates considered that specific forms of technical knowledge arising from economics and traffic engineering disciplines were unfairly privileged in decision-making processes.

Across the eight advocates interviewed, three prominent points of contestation arose as common themes. The first point focused on the technocratic logics driving transport infrastructure decisions. Technical tools for forecasting future demand created the perceived need for ongoing expansion of road infrastructure, limiting the potential to improve the quality and coverage of public transport services. Second, advocates asserted the spatial dimension of transport infrastructure: highlighting that transport infrastructure is not only a conduit for movement, but comprises a large share of public 
space in the city. Therefore, provision of space across travel modes has an impact on the potential uses of these public spaces, and relative provision for the mobility across transport modes. Lastly, social media practices articulated the lived experience of alternative travel behaviours, constructing knowledge on the everyday experience of cities, and infrastructure's influence on this experience.

\subsection{Contesting technocratic logics: traffic forecasting and 'revealed preference'}

The dominant point of contestation centred on the pervasive influence of traffic engineering disciplines. The modelling approaches used to estimate traffic flows, and in turn, demand forecasts, were seen as a major barrier to encouraging a shift to public transport and active travel modes. Advocates challenged the use of model outputs for decision-making, in place of individual judgements: "The biggest challenge that we're facing at the moment is around the actual modelling, and there's an overreliance on what the computer says is going to happen, rather than actually looking at what happens". The assumptions embedded within traffic models ran directly counter to the aims of advocates to intentionally restrict private vehicle capacity to reallocate space to alternative travel modes. The use of traffic forecasting models as analytical devices was criticised as a method of closing down debate, rather than providing genuine insight into the nature of the transport problem, to inform decision-making or deliberation. Advocates articulated the different ways in which model outputs could be used: "Modelling is created with a good intention... but it ends up being used as a decision-maker, rather than a decision-influencer". The perceived absence of expert interpretation of model outputs, characteristic of technocratic governance, is seen as a key barrier to enabling change in the city's transport system.

At a broader scale than a single road scheme, the use of traffic forecasting within the National Long-Term Transport Demand Model was also contested. Figure ?? illustrates the successive annual estimates of future growth in VKT, against the actual values plotted in black. This chart was initially produced for a report commissioned by New Zealand's Ministry of Transport and republished on the Greater Auckland blog to highlight how the lack of ongoing monitoring to adjust the model's parameters when it repeatedly over-estimated future demand. This example is emblematic of the challenges for technical modelling tools to conceive of transformative change. The logic of forecasting is at odds with the purpose it is supposed to serve - as argued by Næss and Strand (2012), urban transport systems are complex, open systems and the possibility of predicting the outcome of a proposed intervention into such a system is very limited using models based on closed systems.

Figure 1: Comparison of official forecasts for future travel (vehicle kilometres travelled) and actual results (Ministry of Transport 2014)

The second form of technical expertise challenged by advocates was the economic concept of 'revealed preference', ${ }^{2}$ which states that individual preferences are reflected in what they purchase. The use of this economic concept for transport decision-making is arguably a misinterpretation of the initial notion proposed by Samuelson (1948). Samuelson proposes that revealed preference is inferred when consumer behaviour is observed with different combinations of goods, and different prices however these test scenarios are impossible to carry out for urban transport systems. Nonetheless, transport planning treats current travel behaviours and modal share as a reflection of individual 
preferences, despite disparities in the price and level of service for different modes. Advocates identified 'revealed preference' as a rhetorical device that constructs a limited scenario of the future, with little scope for changes in travel behaviour "It is all about language - when they say 'revealed preference', they build a world where's there's only one success - only one joined-up way of moving around the private vehicle, and then they say, 'everyone's doing it, this reveals that this is really what everyone wants'." In the context where the level of accessibility available for private vehicle travel was substantially higher than any other mode, advocates perceived that invoking the concept of revealed preference misrepresented the genuine preferences of individuals who may have opted for public transport, cycling or walking if transport infrastructure supporting these forms of travel was dramatically improved.

Advocates contested forecasting and revealed preference as overly technocratic approaches, however in other instances they adopted similarly technocratic methods as a tactical approach to influence decision-making. For example, promotion of cycling in Auckland was catalysed by costbenefit analysis, a tool which has received considerable criticism for over-reliance on travel time savings and ignoring induced demand (Beukers et al. 2012, Mackie and Preston 1998). The legitimacy of this tool in the New Zealand context meant that a cost-benefit ratio for proposed cycle lanes was an effective tactic to justify investment: "You can push for other reasons, climate change, exercise, health, compact city stuff... but there was some work out of the university which came out with great figures, 20:1 investment returns, which was just enough for a media soundbite for politicians, it's a really clear economic argument - so that's where we learnt our narrative for cycling". Adopting existing decision-making tools to argue for alternative transport modes reinforces CBA as the authoritative measure of value for transport but reveals the strong legitimacy attributed to quantitative evidence generated by accepted analytical methods (Kebłowski and Bassens 2017) in the local context.

\subsection{Reasserting transport infrastructure's value as urban space}

Going beyond the decision-making tools for transport infrastructure, advocates also prompted a more fundamental change in thinking on the purpose of transport infrastructure and the multiple functions that it serves in cities. Technical expertise on transport systems perceived them as mobility systems first and foremost, designed to support the efficient movement of vehicles.

Over recent decades, catering for the private vehicle has pervaded the planning, design, and in turn the individual experience of moving about the city (Bean et al. 2008). Valuing the mobility of vehicles over other uses of urban space for pedestrians, cyclists and transit users led to ongoing expansion of road capacity in Auckland. Normative assumptions on the superiority of travelling by car and enthusiastic adoption of new motorway systems in the 1950s ushered in automobility and land-use patterns that locked in this behaviour. Auckland's transport history was presented as a key narrative by advocates to emphasise the intentional decisions that shaped the city's spatial form: "[Auckland] made a deliberate normative decision to look at the US and get quite excited about that futuristic approach, and sort of put all their eggs in the motorway basket, rip out the tram network, and not really spend any money on public transport for 60 years... they created that situation, it wasn't necessarily a natural outcome".

The generally accepted paradigm for urban mobility by government agencies deemed higher 
capacity road infrastructure and faster travel speeds as improvements to the transport network. However, advocates argued for an alternative perspective, framing streets and roads as multifunctional spaces: "we were trying to articulate a narrative, a story which countered the assumptions - always about how to increase safety and efficiency and move more, faster - whereas we're saying actually, there's going to be congestion, but it's not about whether there's congestion or not, it's whether there are choices we make around what we travel in". The ongoing promotion of transport choices and alternatives attempted to broaden the incumbent assumption that the movement of vehicles should be privileged over other travel modes. Advocates showed how engineering standards and practices codified this assumption: "as I've dived into various engineering standards, [I see] how embedded the automobile dependency is, in terms of how you see pedestrians and cycling as an afterthought, and the assumption that everyone drives - wherever you look, the transport modelling or street design or even the professionals involved".

These underlying assumptions undermined efforts to support a shift to more sustainable travel modes. Advocates countered this by emphasising the scarcity of land in cities, promoting the value of urban space for people to use and move through without requiring a vehicle. As one interviewee recounted, transport planning did not meaningfully differentiate between the benefits and costs of transport infrastructure in urban and rural areas: "Urban issues are scale issues, they're spatial issues - it's all about spatial efficiency... The highway, for example, it's a really different thing in the countryside to the city, and the dis-benefits of it multiply enormously in the city... in rural [economies] it's about distance and efficiencies over distance: space is a thing to be conquered at length, it isn't about width". Figure 2 shows a photo posted on the Greater Auckland blog, illustrating the changes in the streetscape after a 'shared space' upgrade and highlighting the change from a street heavily occupied by cars, to one used by pedestrians, cyclists and outdoor diners at a café.

Figure 2: Before (above) and after (below) photos of a 'shared space' upgrade in the city centre, published on the Greater Auckland blog (Greater Auckland, 2015)

\subsection{Infrastructure and everyday experience}

The third point of contestation centred on the limited appreciation of everyday experience within transport planning. Technical knowledge embodied in policy, design standards and appraisal tools gave very limited recognition to the impacts of the built environment on the individual, experiential quality of the city.

Decades of automobile dependence influence the dominant mobility cultures in Auckland. Bean et al. (2008) shows how car ownership in Auckland held strong social importance, and it residents thought it unimaginable to live their everyday lives without a car - however traffic congestion imposed 'severe limitations on their lives and their personal time, with trips taking exceptionally longer at rush hour... Parents especially found it difficult to balance long commutes with their desire to spend time with their children" (Bean et al. 2008 pp.2840). Technical expertise relies heavily on technical models predicting traffic flows, and economic conceptions of value that give no intrinsic value to individual experience, beyond that which may be capitalised into prices or property values.

Advocates promoted an alternative perspective that elevated the experiential dimension of urban 
travel and promoted the benefits of more reliable and convenient public transport services, cycling and walking infrastructure and improved urban design. The absence of any experiential dimension in technical knowledge created a challenge for advocates to communicate and validate this dimension: "Infrastructure is really important for the shape of the city and people's everyday life, but the problem is connecting the two, the processes are very dry and have a huge amount of technical weight". However, this alternative knowledge had a twofold impact: firstly, from a planning perspective, it privileged the value created by transport infrastructure to improve the lived experience in a city, with direct impacts on quality of life. Secondly, appealing to everyday experience implied that expert knowledge and the way that we know a city can be specific to the individual. This claim gave renewed legitimacy to personal experiences of travelling in Auckland, reflected in its success as a strategy for advocates:

"When we clicked... it was when it suddenly became about your experience, not this broader idea of the way a city should work, or the technical details or specification. It was: you can't afford a house - maybe you would be able to if the city looked like this. And people liked that idea of what the city would look like." As a way of translating the technical details of transport infrastructure to engage the wider public, appealing to individual experience give these issues credibility and also legibility to non-specialists.

One advocate's description of commuting to work further illustrates the relationship between experience and knowledge. The interviewee recounted his understanding of the connection between spatial form and transport was formed, capturing the interplay between experience and knowledge of the city:"I had this rare experience of a five minute walk to the train station, and then a three minute walk from the train station to the office. No one else has that, and it distorts everything - in quite an exciting way, I think, mentally. So I saw this [apartment] building, and it was maybe twenty dwellings, on a site that would have once held two. And I was like, oh, that's it... it's not a particularly hard thing to grasp in your head, but sometimes it takes a moment like that to really understand how it would look. If we can build more [apartments] quickly and there's the transit infrastructure to move them around, it seems like fucking paradise to me.". In automobile-dependent cities like Auckland, a large share of the population have lived mostly in urban areas dominated by private vehicle travel, detached dwellings and limited public transport provision. The absence of individual experience of alternative ways of living and moving around the city undermines the legitimacy of expertise that advocates for higher-density development, public transport and active travel modes.

Most interviewees reflected on their own travel habits and experiences in the city. While this reinforces the importance of experience, in this case, it is also problematic. All eight advocates interviewed were male, European, in professional roles or university, and unlikely to experience much of the discrimination or marginalisation experienced by those in other racial, ethnic or class groups. Section 6.2 discusses this in more detail, in the context of the tactics adopted for advocacy.

\section{Tactical approaches to contesting knowledge}

The tactics employed to contest and renegotiate urban transport knowledge in Auckland show how the potential value created by infrastructure was limited by isolating expert knowledge to the technical disciplines. As illustrated in the previous section, technical expertise acted as a barrier to actively encouraging shifts toward more sustainable and equitable travel options, improving the quality of the 
city's public spaces and considering how transport infrastructure can improve everyday experiences and quality of life. These tactics reveal the role of socially-constructed knowledge and knowledge flows, in shaping the 'discursive and tactical' realm of governance (McFarlane and Rutherford 2008).

Tactics also reveal the politics of knowledge production, as advocates sought to garner influence without expert authority, to mobilise a public response to local government and transport authorities. Advocates' tactics employed direct advocacy with local officials alongside social media platforms to build visibility and disseminate alternative forms of expertise. The use of the internet was central for both knowledge production and deliberation, showing how spaces for public deliberation can be created in the digital realm.

\subsection{Countering the postpolitical: Extending the public sphere online}

Online blogging and social media technologies provided a platform to extend the public sphere into more democratic and deliberative online spaces. Advocates reflected that this allowed more objective perspectives to contribute to the public debate on Auckland's transport, alongside established industry groups and lobbyists: "the most important thing [the blog] ever did was raise the quality of the public conversation about transport in Auckland, and put a perspective to the debates that didn't necessarily have a self-interest". Similar to the case of transport campaigners in Melbourne (Legacy 2016), this tactic countered the postpolitical condition in urban governance by creating new spaces for public engagement. The tactic was seen to restore agency to the public to share their views and counter the perceived hegemony of transport authorities over decision-making: "The first thing the blog does is it says, we - and meaning the reader as well - can have a view on this. Don't let these people - who are of course working in our name - don't let them just suit themselves". Online spaces leveraged the internet's communicative potential to disseminate new information rapidly and facilitate debate on current issues, using Twitter and an active comments section on blog posts. The high level of reader engagement for the Greater Auckland blog is reflected in the average 27 comments received per post, between 2008-2017. Several active members of the group developed their knowledge of transport planning as readers of the blog, and progressed to join the small team responsible for writing blog posts regularly.

Underpinning the creation of online spaces for debate was a hypothesis that limited public engagement and deliberation was not due to a lack of concern of the city's transport, but rather the absence of opportunities to engage in meaningful debate. The combination of blogging on transport news to provide a steady stream of information, alongside the feedback and commentary on Twitter, stimulated this latent demand and developed a more coherent body of knowledge and evidence to inform the public on transport issues. It also allowed advocates to mobilise public opinion to support specific projects or planning decisions in Auckland: "one thing that has always centred us around how we communicated is, we have this belief that people want to take action on these issues in Auckland, but currently, don't know how... we're just articulating that in a clear story, and giving people an opportunity to act on that intuition".

Utilising the internet's communicative potential was instrumental to debate different forms of technical expertise. As a virtual 'public sphere' (Dahlgren 2005, Papacharissi 2002), the internet supports deliberative critique of expert knowledge, and formation of tactical coalitions, similar to that 
seen in American cities (Trapenberg Frick, 2016). Information was rapidly disseminated to the public through blog posts, Twitter and other social media, explaining transport issues to non-specialists: "The internet has enabled what we might call muggles ${ }^{3}$ to have an informed view". In particular, the blog site functions as a rhetorical public (Pang and Goh 2016) for deliberation, allowing any user to debate, question, and clarify expert claims: "we have actively fostered more of a community with [the blog], we want people to engage constructively with comments... we attempt to maximise access to facts, and to pour as much daylight on them, get them out there, and to crowdsource our understanding of them, to get as many inputs and counterfactuals and different ways of looking at it". Online spaces for engagement also provided a source of knowledge for mobilisation, as groups frequently linked to stories published on other international urban media sites, and a range of urban experts and consultants from cities in North America, Europe and Australia.

The internet also provided the sources of expert knowledge for advocates to learn, providing access to a wide variety of media sources, blogs and news sources. Advocates used Twitter extensively to access this knowledge, and facilitate debate on current issues in Auckland: "the great opportunity that's opened up with the internet is the dissemination of facts - what we do is only possible because of the internet in two ways - it's obviously our platform for communication, but it's also our source of information.". Spatial analysis of Twitter data illustrates the global flows of information supported by social media platforms. Figure 3 shows the geographic distribution of accounts from which Greater Auckland, Generation Zero and Campaign for Better Transport retweeted, based on a sample tweets from March 2017. The figure shows how international knowledge circuits are strongly concentrated in areas across Northern Europe, coastal regions of North America and Australia. While the distribution of locations shown in the figure largely reflects English-speaking regions of the world, it nonetheless shows that while Twitter enables rapid international communications, this does not always result in diverse international networks across the platform.

Figure 3: Geographic distribution of tweets. Note: Tweets from the same location are clustered and appear more dispersed, particularly within New Zealand where tweets were mostly in Auckland, with smaller groups in Wellington and Christchurch.

\subsection{Promoting a narrative centred on change}

The second tactic adopted by advocates sought to shift the dominant narrative to centre on change in Auckland, instead of reinforcing the status quo. This shift in narrative was necessary to credibly challenge the technical expertise that acted as a barrier to change for Auckland's transport: "we had a very clear plan to change the narrative around it... the national dialogue is that you fund things that are working, and we see local government as a change-maker, and you can change behaviour". The Greater Auckland blog illustrates this narrative, with a series of posts on local and national issues in urban transport planning, re-posted articles from other popular blog sites and urban media, interspersed with travel diaries from advocates' overseas holidays that examine urban planning and transport provision in cities such as Portland, Amsterdam and Tokyo. This approach reframed the transport 'problem' in ways that allowed new expertise to gain legitimacy, by focusing on potential change instead of historic evidence: "Traditionally, if you advocate for public transport, it's 'we want trains because we like trains, or we think there should be trains here... Not saying, 'what are the changes we're 
experiencing, how much do we actually need to move, and why do we need to do that over something else...it's about highlighting that these things are growing (or not), telling a story about how Auckland is changing". Centring knowledge on the narrative of change gave an entry point for new expertise, often drawn from international consultants including Jarrett Walker, Mike Lydon and Richard Florida, to gain legitimacy in the local context.

Advocates made a concerted effort not to side with established political parties, although this extended to a predominantly depoliticised approach to contestation. Interviewees reflected that contestation avoided the underlying values or distributional impacts of transport investments: "I think the best way of dealing with the politicians is to not deal with it but to talk technically and economically."

The visions set out by three of the four groups, summarised in Table 1 , framed the imperative for change in the context of a bigger challenge, with the city's future prosperity at stake, distinctly similar to the approach of progressive urbanists in California who 'adeptly positioned their obstructed efforts at placemaking as part of a much grander fight for the future fortunes of the city.' (Stehlin and Tarr 2017). While this tactic effectively built legitimacy, the changes promoted for Auckland gave limited attention to distributional issues and social equity. Transitioning to more environmentally sustainable travel options, intensification and better quality urban design were positioned foremost as a technical solutions.

The interviews unanimously showed that the advocates working in Auckland were well-intentioned and sacrificed significant time and effort in their work to improve the city. However, inequality and distributional issues were perceived to be problems that advocacy should not, or could not, be expected to address. Those interviewed held a range of perspectives. Some viewed social issues to be largely independent to their focus: "social justice is not a huge driver for the blog, we are very much more focused on effectiveness, so, cost effectiveness, BCRs, we don't care too much who benefits from transport policy, provided that the benefits exceed the costs" although where the broader goal of 'cost effectiveness' included opportunities to address equity issues, advocates included these in their proposed solutions: "where we can identify a policy that disadvantages low-income groups, or alternatively a policy that would definitely benefit low-income groups. In the housing policy space, we talked about apartments, and we have written a lot about how more compact dwellings are hugely beneficial for low-income households in particular". Some positioned themselves as complementary to other, more radical groups: "we tend to be very practical about that sort of stuff, which makes us appear a lot less morally driven than we actually are... we work with a lot of groups who I think are far more toward the kind of 'Occupy' scale of activist groups, who tend to think of us as corporate sellouts, but my personal belief in it is that you need all of those groups, because you need the people pushing on the far edges to balance out us pushing the middle, a little bit of the time". Others perceived that promoting change on the grounds of social equity was not likely to win campaigns: "that's where our solutions-based campaigning comes from, we don't run campaigns that we think we'll lose... some organisations run campaigns because they think it's the right thing to do, someone has to stand up for this - we don't run campaigns we think we're going to lose because it's not worth our time or our supporters time". While those interviewed readily acknowledged inequalities and the marginalisation of certain populations in Auckland, advocating for social justice was perceived as a futile approach compared to the 'economic argument': "if you can make an economic argument for something which will ultimately clean up your social problem, address it, then it's much more likely to actually happen, and I'm much more interested in the method by which a thing could happen than by, what is your moral case - because people can make a moral case, but 
nothing actually happens". In this way, the approach taken to counter the postpolitical, technocratic governance of transport in Auckland had only minimal engagement with distributional issues, and in some respects maintained the depoliticisation of transport. In light of growing inequality in Auckland, this raises questions over who benefits from the future city envisioned by advocates.

\section{Conclusion}

Reflection on this case study reveals the intersection between the postpolitical condition and policy mobilities within processes of expert knowledge production. The activities of transport and urban planning advocacy groups in Auckland sought to contest the credibility of official expertise in Auckland by drawing from international examples and using social media platforms to communicate and advocate for alternative travel options in the city. Online spaces that enabled rapid dissemination of information, and communicative deliberation across a group of self-selected participants, created an extension of the public sphere into digital space. This extension proved to be effective in countering the postpolitical condition by creating new platforms and online spaces for discussion and deliberation, which gained popularity with a local audience of practitioners and the general public. Social media platforms, including blogging and Twitter, were particularly effective in disseminating this expertise, drawing from internationally-mobile policies already in use in cities such as Vancouver, Portland, Amsterdam, London and Melbourne. This finding suggests that non-government actors may be as effective at facilitating policy mobilities as state actors, drawing directly from the social media accounts of consultants, transport and planning practitioners, and government officials from other cities.

This case illustrates how the internet has enabled advocates to re-order the polity of transport in Auckland, by creating new online spaces for deliberation and contestation. However, this re-ordered polity has relatively superficial engagement with the politics of transport, regarding distributional issues and the potential marginalisation of different groups according to income, age, gender and race. Therefore in some aspects, the activities of advocates maintain the depoliticisation of transport although as raised by Stehlin and Tarr (2017), this may arise from a limited appreciation of advocates' positionality rather than a direct attempt to subvert the interests of disadvantaged groups. This minor critique should not overshadow the significant contribution made by advocacy groups in Auckland over a relatively short period. The remarkable shifts in transport planning and policy observed in Auckland that will leave a legacy for both current and future generations. Rather, it is a risk for expert knowledge to continue to maintain 'blind spots' to underlying inequities and distributional impacts. Developing broader alliances with community groups and local researchers can support ongoing learning across advocacy networks, to shed light on the politics of transport and address potential risks of overlooking social equity and marginalisation.

\section{Notes}

\footnotetext{
${ }^{1}$ The reasoning behind this decision is explained further by Mees and Dodson 2007)
} 
${ }^{2}$ The notion of revealed preference states that consumer behaviour can be equated to consumer preferences, by testing consumer behaviour under a variety of prices (Samuelson 1948)

${ }^{3}$ Muggle is a colloquial term for a person without specialist knowledge or skills in a given field 


\section{References}

Bean, C., Kearns, R., and Collins, D. (2008). Exploring social mobilities: Narratives of walking and driving in Auckland, New Zealand. Urban Studies, 45(13):2829-2848.

Beukers, E., Bertolini, L., and Te Brommelstroet, M. (2012). Why Cost Benefit Analysis is perceived as a problematic tool for assessment of transport plans: A process perspective. Transportation Research Part A: Policy and Practice, 46(1):68-78.

Bocking, S. (2006). Constructing urban expertise: Professional and political authority in Toronto, 1940-1970. fournal of Urban History, 33(1):51-76.

Borjesson, M., Brundell-Freij, K., and Eliasson, J. (2014). Not invented here: Transferability of congestion charges effects. Transport Policy, 36:263-271.

Bush, G. (2014). From Survival to Revival: Auckland's Public Transport since 1860. Grantham House Publishing, Wellington, New Zealand.

Castells, M. (2008). The new public sphere: global civil society, communication networks, and global governance. Annals of the American Academy of Political and Social Science, 616(1):78-93.

Chapman, R., Howden-Chapman, P., Whitwell, K., and Thomas, A. (2017). Towards zero carbon? Constrained policy action in two New Zealand cities . Australasian fournal of Environmental Management, 24(2):97-116.

Cohen, D. (2017). The myth of municipal political will: The politics of collective consumption and the failure of Michael Bloomberg's congestion charge. In American Association of Geographers Annual Meeting, Contradictions of the Climate Friendly City 1: Critical Perspectives on Urban Climate Change Mitigation and Adaptation, Boston, MA.

Dahlgren, P. (2005). The internet, public spheres, and political communication: dispersion and deliberation. Political Communication, 22(2):147-162.

Greater Auckland (2015). Photo of the day - O'Connell Before and After. Accessed 18 December 2017, https://www.greaterauckland.org.nz/2015/02/19/ photo-of-the-day-oconnell-before-and-after/

Harris, C. (2005). Slow train coming: the New Zealand state changes its mind about Auckland transit, 1949-56. Urban Policy and Research, 23(1):37-55.

Healey, P. and Hillier, J. (1996). Communicative micropolitics: A story of claims and discourses. International Planning Studies, 1(2):165-184.

Hickman, R. (2014). Urban dispersal and high motorisation (Auckland). In Transport, Climate Change and the City, chapter 7. Routledge, London, United Kingdom.

Hodson, M., Marvin, S., Robinson, B., and Swilling, M. (2012). Reshaping Urban Infrastructure: Material Flow Analysis and Transitions Analysis in an Urban Context. Fournal of Industrial Ecology, 16(6):789-800.

Imran, M. (2015). Discursive barriers to sustainable transport in New Zealand cities. Urban Policy and Research, 33(4):392-415.

Kebłowski, W. and Bassens, D. (2017). "All transport problems are essentially mathematical": The uneven resonance of academic transport and mobility knowledge in Brussels. Urban Geography.

Kirby, A. (2013). Cities and powerful knowledge: An editorial essay on accepted wisdom and global urban theory [Part I]. Cities, 32(1):S3-S9.

Labour (2017). 2017 Election Policy - Transport. Accessed 17 December 2017, http : / wWw . labour . org. $\mathrm{nz} /$ transport

Legacy, C. (2016). Transforming transport planning in the postpolitical era. Urban Studies, 53(14):3108-3124.

Mackie, P. and Preston, J. (1998). Twenty-one sources of error and bias in transport project appraisal. Transport Policy, 5(1):1-7.

Marsden, G., Frick, K., and May, T. (2012). Bounded rationality in policy learning amongst cities: lessons from the transport sector. Environment and Planning A, 44(4):905-920. 
Mayer, M. (2013). Multiscalar mobilization for the just city: New spatial politics of urban movements. In Nicholls, W., Miller, B., and Beaumont, J., editors, Spaces of Contention, pages 163-196. Ashgate, Farnham, United Kingdom.

McArthur, J. (2017). Auckland: Rescaling governance and post-suburban politics. Cities, 64:79-87.

McCann, E. (2010). Urban Policy Mobilities and Global Circuits of Knowledge: Toward a Research Agenda. Annals of the Association of American Geographers, 101(1):107-130.

McFarlane, C. and Rutherford, J. (2008). Political Infrastructures: Governing and Experiencing the Fabric of the City. International fournal of Urban and Regional Research, 32(2):363-374.

Mees, P. and Dodson, J. (2007). Backtracking Auckland?: Technical and Communicative Reason in Metropolitan Transport Planning. International Planning Studies, 12(1):35-53.

Ministry of Transport (2014). Historic New Zealand light vehicle traffic forecasts vs actual growth. Accessed 17 December 2017, http://www.transport.govt.nz/ourwork/ keystrategiesandplans/strategic-policy-programme/future-demand/.

Mould, O. (2014). Tactical urbanism: the new vernacular of the creative city. Geography Compass, 8(8):529-539.

Næss, P. and Strand, A. (2012). What kinds of traffic forecasts are possible? Fournal of Critical Realism, 11(3):277-295.

Pang, N. and Goh, D. (2016). Can blogs function as rhetorical publics in Asian democracies? An analysis using the case of Singapore. Telematics and Informatics, 33:504-513.

Papacharissi, Z. (2002). The Virtual Sphere: The Internet as a Public Sphere. New Media \& Society, 4(1):9-36.

Peck, J. (2011). Geographies of policy: From transfer-diffusion to mobility-mutation. Progress in Human Geography, 35(6):773-797.

Samuelson, P. (1948). Consumption theory in terms of revealed preference. Economica, 15(60):243-253.

Stehlin, J. and Tarr, A. (2017). Think regionally, act locally? gardening, cycling and the horizon of urban spatial politics. Urban Geography, 38(9):1329-1351.

Swyngedouw, E. (2010). Impossible sustainability and the post-political condition. In Cerreta, M., G., C., and V., M., editors, Making Strategies in Spatial Planning, volume 9 of Urban and Landscape Perspectives, chapter 11, pages 185-205. Springer.

Swyngedouw, E. (2017). Unlocking the mind-trap: Politicising urban theory and practice. Urban Studies, 54(1):55-61.

Takhteyev, Y., Gruzd, A., and Wellman, B. (2012). Geography of Twitter networks. Social Networks, 34(1):73-81.

Trapenberg Frick, K. (2016). Citizen activism, conservative views \& mega planning in a digital era. Planning Theory \& Practice, 17(1):93-118.

Van Damme, S. (2013). Is it possible to write a history of urban knowledge? Metropolitics. Accessed 5 August 2017, http: //www.metropolitiques.eu/Is-it-possible-to-write-a-history. html

Vigar, G. (2017). The four knowledges of transport planning: Enacting a more communicative, transdisciplinary policy and decision-making. Transport Policy, 58:39-45.

Williamson, W. and Ruming, K. (2017). Urban consolidation process and discourses in Sydney: unpacking social media use in a community group's media campaign. Planning Theory \& Practice, 18(3):428-445.

Wood, A. (2015). Multiple Temporalities of Policy Circulation: Gradual, Repetitive and Delayed Processes of BRT Adoption in South African Cities. International fournal of Urban and Regional Research, 39(3):568-580.

Zizek, S. (1999). The ticklish subject. The absent centre of political ontology. Verso, London, United Kingdom. 